\title{
DE AMORES A TRISTIA, LA METAMORFOSIS DE OVIDIO A TRAVÉS DEL LIBELLUS
}

\author{
José María SÁNChez Galera \\ jsgalera@aol.com
}

\section{RESUMEN}

Durante los siglos I a. C. y I d. C. la literatura romana refleja la asimilación del libro en tanto que elemento físico que contiene el resultado de un esfuerzo creativo e intelectual. La poesía latina de esa época explica cómo el volumen de papiro constituye el soporte de transmisión de obras y de autores. El presente estudio, centrado en Ovidio, describe el contraste entre su obra erótica y la poesía del exilio, a partir del gran cambio que experimenta el uso del vocablo libellus. El libellus sirve, por tanto, como «termómetro» del estado vital de Ovidio.

Palabras Clave: literatura latina, cultura libresca, Ovidio, libellus, Tristia.

\section{AbSTRACT}

Roman literature during the period 1 st century BC -1 st century AD expresses the assimilation of book as a physical object containing the result of a creative and intellectual effort. Latin poetry shows how the papyrus volumen constitutes a hardware for the transmission of works and writers. The following lines, focused on Ovid, describes the sheer contrast between his erotic works and his exile poetry; based on the deep shift experienced by the libellus. In other words, the libellus is a «thermometer» of Ovid's state of mind.

KEY WORDS: Latin literature, bookish culture, Ovid, libellus, Tristia. 
Ovidio $^{1}$ (43 a. C. - 17 d. C.) nace un año después del asesinato de Julio César, por lo que su vida transcurre ajena a toda la crisis política y convulsiones sociales anteriores a la pax Augusta. Estas circunstancias se reflejan en su obra, y se suman a la herencia poética que recibe de sus antecesores, como Catulo y Horacio. De hecho, desde muy joven mostró escaso interés por la oratoria forense, como recordaría su compañero de escuela Séneca el Retórico ${ }^{2}$. Ovidio es un gran entusiasta de la poesía, sobre todo de la temática sentimental y erótica. Gracias al ingenio e intensidad de sus versos, será un autor admirado por casi todas las generaciones posteriores, en especial durante la Edad Media. Debido a este continuado reconocimiento de su prolija obra, podemos leer una amplia gama y número de sus poesías: sus portentosos y elaborados Fasti o Metamorphoses, la obsesiva desolación de sus Tristia y Epistulae ex Ponto, elegías que muestran su devoción por Tibulo y Propercio -Amores-, la agudeza de sus Heroides, o la esmerada y urbanita veleidad de su Ars amatoria.

Dentro de toda la producción ovidiana, nos limitaremos a analizar la diferencia de matices y connotaciones entre el término libellus de Ars amatoria o Amores ${ }^{3}$ y el libellus de Tristia ${ }^{4}$. Así, frente a la frescura y el desparpajo chisposo que rezuman los libros eróticos, en Tristia el significado y la importancia del libellus adquiere no sólo la cariñosa gravedad de la elegía, sino un constante protagonismo. En la obra del exilio, el recurso al libellus es parte de un proceso de humillación y casi de servilismo; a la postre, el libellus de Tristia resulta casi opuesto al de las otras obras. Desde Tomis, el autor se lamenta de que sus consejos amatorios, y quizá otra causa añadida, le hayan acarreado la soledad y la inmersión en un paraje marcado por la incultura. Sin entrar en el proceso que llevó a Ovidio a la relegatio en los confines del mundo civilizado, lo relevante para el presente estudio es la manera como en Tristia se describe aquel país inhóspito, y qué alivio pueda suponer el libellus en esa situación.

La poesía de Ars amatoria y Amores «nace y se desenvuelve en el marco imprescindible de la vida urbana, de las relaciones sociales en la gran ciudad» ${ }^{5}$. De hecho, los libros eróticos constituyen la sublimación de la urbanitas, el refinamiento y, hasta cierto punto, los aspectos frívolos de la poesía de Calímaco y Catulo. Visto así, el mundo ovidiano descrito en estas obras se opone a la virtus de la sobriedad tradicional, se aleja completamente de la rusticitas: «Rústicos, incultos -en definitiva, no urbanos- son todos los que aplican con rigor las normas del matrimonio, la moral arcaica ${ }^{6}$. En este sentido,

${ }^{1}$ Esta colaboración es una parte del Trabajo de Fin de Máster titulado «El liber y libellus romanus, su valor literario y relevancia. De Plauto a Marcial», llevado a cabo dentro del Máster El Mundo Clásico y su proyección en la Cultura occidental (Facultad de Filología, UNED) bajo la tutoría de la doctora Pabón de Acuña.

2 «Declamabat autem Naso raro controversias et non nisi ethicas; libentius dicebat suasorias. molesta illi erat omnis argumentatio» (Controversiae II, 2:12). Según BICKel, Ernst (2009) en Historia de la Literatura Romana, Madrid, Editorial Gredos, p. 648, «la escuela de oratoria no tenía [para Ovidio] otro significado que el de pasatiempo del espíritu».

${ }_{3}$ Para los textos de estas dos obras, usamos las ediciones de Ramírez De Verger, Antonio y Socas, Francisco (1991 y 1995), Madrid, Alma Mater (CSIC).

${ }^{4}$ No incluimos en el presente estudio Epistulae ex Ponto, pues Tristia ya aporta un buen número de ejemplos para el propósito de este artículo. En este caso, usamos la edición de BAEZA Angulo, Eulogio (2005), Madrid, Alma Mater (CSIC).

5 González Iglesias, J. A. (1997) en Introducción de Amores. Arte de amar de Ovidio, Madrid, Cátedra, p. 56.

${ }^{6}$ Ibid.pp. 56-58. Cfr. Ars I, 672. 
el primer valor del libellus es una mezcla de la ligereza del contenido y de cierto orgullo de Ovidio por dedicarse al «género chico», en vez de a la gran poesía de autores como Ennio o Virgilio ${ }^{7}$.

Esta valoración encaja con los versos en que Ovidio, tras comparar el viaje de Corinna con periplos de los personajes legendarios del «gran género» de la literatura ${ }^{8}$, contrapone los peligros de la travesía marina con la seguridad del lecho, e introduce una conexión nueva entre erotismo -«torum»- y la lectura de libros pequeños -«legisse libellos»-, en este caso, repertorio de correspondencia privada, diario personal.

El epigrama que sirve de proemio a Amores, además de incluir la palabra «libelli» en la primera línea, incide en la ligereza -«levior»- y en la sencillez del formato. Por otra parte, este epigrama apunta algunas notas acerca de las modificaciones de la edición, pues afirma que se ha pasado de cinco a tres volúmenes, quizá por abreviar el contenido, o porque se trate de una edición corregida. Asimismo, en esta introducción los libros se presentan al lector en primera persona, lo que supone un tópico o recurso de prosopopeya que Ovidio y otros autores del libellus influidos por lo alejandrino emplean con regularidad. Estos primeros versos hablan de «leer» y de «recientemente»-«modo»-, de «novedad», lo cual enlaza con el verso I:2 de Catulo. Se alude al placer de la lectura; a la poesía como divertimento y juego. Sin duda, se percibe una lograda conexión entre deleite, técnica, literatura y erotismo; el sexo es gozar, el «librito» enseña las artes amorosas, y por tanto, el libellus es placer e ingenio por partida doble.

Más adelante, el autor afirma que su amada alcanzará fama perenne gracias a su poesía ${ }^{9}$, lo que supone una alusión a otro de los tópicos en los autores del libellus, y que se irá retomando en ulteriores etapas históricas ${ }^{10}$ : la inmortalidad gracias al arte de las letras - gracias a la diosa Minerva-, no debido a la fuerza, la espada o la corona. Es el tema desarrollado de modo exclusivo en Amores I, 15 que Ovidio repite en otros pasajes; por ejemplo, cuando sostiene que es capaz de dar inmortalidad, por medio de su ingenio, a aquellos que aparecen en sus «libritos» ${ }^{11}$. El poeta garantiza que sus versos constituyen una riqueza, la del renombre ${ }^{12}$.

Sin embargo, la eternidad que los libritos conceden a la amada no impide que el poeta fracase ${ }^{13}$. Y aquí se enlaza con otro tema, el de «ponerse en venta»y «mostrarse, ofrecerse en público», pues esa es la manera como la amada, al contrario que el autor, ha triunfado: entregándose y vendiéndose a otros «ingenio prostitit illa meo» ${ }^{14}$. A la postre, el poeta solicita que sus escritos no sean olvidados: «nec mea Lethaeis scripta dabuntur

\footnotetext{
${ }^{7}$ En Amores I, 1:1-5, Ovidio se refiere irónicamente a la Eneida, dejando clara su vocación alejandrina. En este sentido, nos permitimos la libertad de comparar el «género chico» español del s. XIX con la poesía de molles nugae de Catulo, Ovidio o Marcial. En concreto, destacamos que ambas tendencias se distancian de la literatura grave, de la poesía trillada y del teatro ampuloso.

${ }^{8}$ Cfr. Amores II, XI:31.

9 Amores I, 10:60-61.

${ }^{10}$ En El Quijote (Primera parte, cap. 2) el protagonista, solo y en su primera salida como caballero, se complace imaginando el momento en que sus hazañas sean escritas y celebradas.

11 «nec, nisi tu, nostris cantabitur ulla libellis» (Amores II, 17:33).

12 Ibid. vv. 27-28.

13 «fallimur, an nostris innotuit illa libellis?» (Amores III, 12:7).

14 Amores II, 17:34.
} 
aquis (...) deve tribus libris, titulus quos signat Amorum, / elige» ${ }^{15}$. Para enfatizar su apego a la obra que ha creado, emplea varios términos relativos al opus: carmina, lege, legas, composita... A la vez, se trata de una referencia de Ovidio a sí mismo, pues cita de manera explícita el título de Amores y el de Epistola (Heroidas) ${ }^{16}$.

La apelación a la propia obra, al tiempo que al tópico del poeta «bohemio» -en el sentido de «fracasado y pobre»-, se recupera en otros lugares de la obra erótica de Ovidio, aunque con una pátina de ficción, y por tanto, festiva, fingida o frívola. El poeta recuerda que las mujeres se ablandan con la poesía, pero prefieren a hombres ricos, pues existe la oposición entre los libelli admitidos por la amada y el poeta mismo, al que se rechaza $^{17}$. Se conecta de esta forma con un tema que desde Salustio viene siendo criticado, y que Marcial y Petronio tratarán con denuedo: las riquezas han desplazado a la cultura, a la hora de establecer el estatus de una persona y su categoría de urbanus. El ruido y el bullicio de la ciudad son palpables en el libellus como billete de entrada o programa del anfiteatro, sentido de este vocablo que Ovidio emplea en una ocasión ${ }^{18}$.

Como consecuencia, el poeta refleja su cariño y satisfacción por su obra, al mentar a sus anteriores entregas o «fascículos» del opus: «illos artifices gemini fecere libelli» ${ }^{19}$. Y también cita Ovidio otros libros que complementan la técnica amatoria, como su tratado sobre cosmética y belleza: «parvus, sed cura grande, libellus, opus» ${ }^{20}$. Es una evidente paráfrasis, por inversión de términos, a la máxima literaria de Calímaco ( $\mu \varepsilon \dot{\gamma \alpha} \beta \iota \beta \lambda$ íov, $\mu \varepsilon \dot{\gamma} \alpha$ какóv). En este caso, un pequeño librito es un gran bien. Dicho con otras palabras, el autor celebra las virtudes de sus libritos, les otorga un orgulloso reconocimiento, aunque aún no los convierte en protagonistas.

Frente a las ocho ocasiones que aparece la palabra libellus en la obra erótica de Ovidio, hay veinticuatro en Tristia y trece en Epistulae ex Ponto. Este notable incremento va acompañado de un tono y una forma muy diferentes en el empleo del término, hasta el extremo de que el libellus a veces habla en primera persona, y en ciertos momentos es la segunda persona, declinado en vocativo. Por eso, resulta muy llamativa una coincidencia de los cinco libros de Tristia: todos comienzan con la palabra liber o libellus en el primer verso, y en tres ocasiones como primera o segunda persona. Asimismo, la obra se inicia con el vocativo «parve» que Ovidio dirige a su libro. Visto de este modo, ese protagonismo del «librito», del «librito afligido», constituye un factor más de contraste entre Tristia y Amores, cuyos títulos ya suponen de por sí toda una evidente antonimia.

El poema Tristia I, 1 es representativo de los principales valores que Ovidio quiere transmitir con el libellus como tema propio: una simulación de la aurea mediocritas en medio de la postergación que supone el exilio, y de ahí la doble faceta del libro, que tanto es vehículo de amistad, como reivindicación cariñosa del «género chico». Así, el poema supone una conclusión o envoltorio del primer libro que Ovidio escribe en el exilio. En este sentido, conviene recalcar que, al contrario que en sus obras anteriores,

15 Ars III, 340 et 343-344. En este caso, no hemos seguido la lectura de RAMÍREZ DE VERGER et SOCAS (1995), sino la de BORNECQUE (1967), París, Les Belles Lettres.

16 «vel tibi compositā cantetur Epistola voce» (Ars III, 345).

${ }^{17}$ Cfr. Amores III, 8:5-6.

18 Cfr. Ars I, 167.

19 Ars III, 47.

${ }^{20}$ Ars III, 206. 
asumimos que el poeta habla de su realidad, y no finge: por fin Ovidio está hablando de sus verdaderos sentimientos. Tal extremo, no obstante, ha sido puesto en duda en los últimos tiempos ${ }^{21}$; si la relegatio o destierro hubiera sido un recurso literario, nuestra interpretación del libellus en Tristia habría de quedar alterada, pues se trataría de un simple juego retórico, y no de una auténtica comunicación protagonizada por el librito en su sentido más físico.

Como decimos, el primer poema ya aborda los aspectos esenciales que se irán repitiendo en todo el resto del opus: el librito como parte íntima del autor, la referencia al «crimen» literario que ha conducido al poeta a una tierra inculta y lejana, la rudeza de su nueva obra, los detalles técnicos de la edición de libros, la amistad, la petición de perdón al emperador Augusto $^{22}$, etc. De este modo, Tristia muestra distancia geográfica, dificultades y vicisitudes del viaje, e identifica el exilio con el frío climático y también la falta o necesidad de cariño. En el libro rezuma la añoranza de la urbanitas, por lo que se exagera toda la tosquedad y barbarie del país; y de estas características se contagia la nueva obra ovidiana, sin pulir, sin alto estilo, sin pretensiones: «nec te purpureo velent vaccinia fuco» ${ }^{23}$, «nec titulus minio, nec cedro charta notetur» ${ }^{24}$, «nec fragili geminae poliantur pumice frontes» ${ }^{25}$, «hirsutus sparsis ut videare comis» ${ }^{26}$. Ovidio llama a su libro parve (I, 1:1), incultus (v. 3), infelix habitum (v. 4), pide perdón por «siqua meis fuerint, ut erunt, vitiosa libellis» ${ }^{27}$. Contrapone sus nuevos libritos a cualesquiera otros de tema alegre y edición vistosa: «felices ornent haec instrumenta libellos» ${ }^{28}$.

La pequeñez ${ }^{29}$ y sencillo estilo de sus nuevos libritos resulta más patente, cuando el propio libro habla en primera persona, y solicita ser acogido en Roma, pues es un peregrino nacido en tierra bárbara ${ }^{30}$. Se presenta como librito humilde que pide amistad y hospitalidad al lector; es un libro cojo ${ }^{31}$, rudo, sin capa de aceite de cedro ni pulido por piedra pómez ${ }^{32}$, procedente del extranjero y por tanto con deficiente uso del latín, libro mal corregido, con tachones ${ }^{33}$. Se trata de una vuelta de tuerca a un tópico inspirado en Calímaco acerca del librito como trabajo fruto de una esmerada dedicación. Porque, así, con ese pretendido desaliño -un grado más de captatio benevolentiae-, la obra de

21 Vid. Baeza Angulo (2005) pp. xiv-xvii (Introducción).

${ }_{22}$ Por ejemplo, Tristia II, 239-250 («neve, quibus scribam, possis dubitare, libellos», 245).

23 Tristia I, 1:5.

24 Ibid. verso 7.

${ }^{25}$ Ibid. v. 11.

${ }^{26}$ Ibid. v. 12.

27 Tristia IV, 1:1.

28 Tristia I, 1:9.

29 Tengamos en cuenta que, excepto el Liber II, cualquiera de los cinco libros de Tristia ocupa la misma extensión en versos que uno de Ars o Amores, o que un capítulo de la virgiliana Aeneis. Se trata del tamaño estándar de los volumina de papiro en que se editan las principales obras de la literatura clásica romana (Horacio, Marcial, epístolas de Plinio el Joven a amigos y familiares, etc.).

${ }^{30}$ Cfr. Tristia III, 1. «missus in hanc venio timide liber exulis urbem» (v. 1).

${ }^{31}$ Cfr. ibid. vv. 11-12. El autor reivindica, igual que en Amores, el dístico elegíaco, un verso «quebrado» que llama la atención por su aparente defecto de armonía. Es uno de los metros del «género chico».

${ }^{32}$ Cfr. ibid. v. 13. Catulo -«cui dono lepidum novum libellum / arido modo pumice expolitum?» (1:12) - ya unió el concepto de pulido físico del papiro (para hacerlo más suave) y pulido literario del verso (para hacerlo más agradable). Visto así, el aspecto tangible del libro es parte de su calidad y de su tono amable. El tacto delicado del papiro es el inicio de un poema redactado con esmero y cariño.

${ }^{33}$ Cfr. ibid. v. 15. Misma idea se transmite en I, 7:33. 
Tristia aspira a despertar compasión, pues el libro en primera persona ruega a Augusto que se reconcilie con Ovidio, padre de los libritos ${ }^{34}$; habla de sus «hermanos»-todos los demás libros del poeta ${ }^{35}$ —; y describe el recorrido que hace, como viajero o paseante en Roma, hasta la Biblioteca pública de Asinio Polión ${ }^{36}$, que fue la primera que acogió a

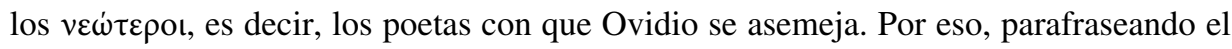
epíteto de Catulo, califica sus obras como doctis libellis ${ }^{37}$.

Los libros que componen Tristia son un trasunto de la metamorfosis sufrida por el propio Ovidio, quien se identifica con la orfandad de sus groseros papiros y libelli. De este modo, el poeta habla del momento en que hubo de quemar sus libros ${ }^{38}$, lo que no implicó su desaparición, pues existían más copias. Compara aquel momento con otro legendario y épico -Altea y su hijo Meleagro-, lo que realza el valor y la inocencia de sus «libritos», como si el poeta fuese una madre y sus libros fueran sus hijas. Además, admite que «crescens et rude carmen erat» ${ }^{39}$, lo que aumenta la sugestiva fuerza del tropo, al equiparar a uno de sus libros con un niño pequeño que necesita alimentarse. Es otra nota añadida sobre el trabajo de pulido que requieren los poemas. Y habla de las Metamorphoses, a las que alude con el título latino de Formae mutatae.

Ovidio recurre, no ya a la antítesis que constituye su mudanza personal y literaria, sino también al contraste entre su derrota y postergación, y la soberanía absoluta del César. Resulta evidente en la abundancia de palabras que se vinculan al destierro, la pena, las amenazas del mar: exulis, luctibus, lacrimis, miser, culpabere, nubila, terra remota. Muy unido a este campo léxico, aparece un elenco de vocablos que significan silencio, miedo o reclusión: tacitus, cave, ignotum, dissimulare, dubitantem, timentem, procul, latitantes. Para subrayar esta sensación desolada, encajan los términos relativos a la tormenta o el mal tiempo, como venti, hiems, procella; y los que recuerden la irritación del césar Augusto y el «delito» que ha acarreado la pena de destierro: crimina, principis ira, casus. En este contexto, Ovidio incluye alusiones a los dioses y Augusto -Octavio es un dios-, y también expresiones idiomáticas de permiso o deber: non licet, decet, opus est, deos, alta Palatia, Caesareamque domum, illa fulmen ab arce ${ }^{40}$.

A lo largo de la obra, el poeta nacido en Sulmona, apocado e impotente ante el princeps, se humilla, se excusa, pide perdón, se arrepiente por momentos: «quid referam libros, illos quoque, crimina nostra $»^{41}$. Dado que su vida ha discurrido fuera de la política, Ovidio no puede mostrar reacción política, sólo literaria. Gran parte del libro II supone una ristra de argumentos en favor de sus obras eróticas; por una parte, afirma que la narración o el estilo de su libro no son reflejo de su propia vida, pues él es vir-

34 «precor, nostro placere parenti» (ibid. v. 57).

${ }_{35}$ Cfr. ibid. vv. 65-66. Sin embargo, el librito evitará ver a los «hermanos» que su padre no debió engendrar. Una de las muchas elipsis para referirse a Ars y Amores.

${ }^{36}$ La descripción del recorrido del libro -en la prosopopeya- es un recurso específico de los poetas que más emplean libellus como hipocorístico. El libellus «amigo y andarín» abunda en la obra de Marcial.

37 Cfr. ibid. v. 71.

38 «sic ego non meritos mecum peritura libellos» (I, 7:19).

39 Ibid. v. 22.

${ }^{40}$ Para las palabras seleccionadas en este párrafo, nos hemos limitado al primer poema de Tristia, tras contrastar que los cinco libros, grosso modo, siguen el mismo patrón.

41 II, 61. 
tuoso $^{42}$. Por otra parte, cita las grandes composiciones de otros poetas muy celebrados, para señalar que también tratan de adulterios, incestos y violaciones. En comparación con varios ejemplos de autores griegos y romanos que abordan temas similares o más graves que los de Ars, en el libro de Ovidio apenas podrían caber todas las referencias de pasiones desatadas en las tragedias, de erotismo descontrolado ${ }^{43}$. Sin embargo, tramas repletas de aborto, homosexualidad y todo tipo de obscenidades -comenta Ovidio- se hallan disponibles en la misma biblioteca pública en que su Ars está arrinconada o casi descatalogada ${ }^{44}$. Por eso quita hierro a su poesía erótica: «non tamen idcirco crimen liber omnis habebit» ${ }^{45}$.

Esa defensa de sus libros amatorios lleva a Ovidio a un despliegue poco usual en la literatura clásica: referencias explícitas, con títulos y autores, a casi toda la poesía que en aquella época se consideraba noble o digna. Y se atreve a incluir sus producciones ${ }^{46}$. Lo cual indica una cultura de biblioteca muy reconocible, aparte de un trato frecuente con directores de biblioteca, como Julio Higinio, a quien se dirige para pedirle cariño hacia su librito: «qualemcumque igitur venia dignare libellum / sortis» ${ }^{47}$. El destinatario es un protector de los «doctos» poetas, y antes solía ayudar a Ovidio a pulir sus textos. Le cuenta que está exiliado, pero señala que la pena no recae sobre sus libritos -sus «hijos»-, que no merecen el castigo y que pueden circular por Roma. Tras citar a Palas Atenea, pide que sea el tutor de este nuevo libro. Se acuerda de sus demás hijos, sobre todo Ars y Metamorphoses, y le pide que los cuide, y que coloque a este nuevo «sin título» junto a los otros, para que lo lean, para que no quede huérfano, pues nació en un país extranjero y es un forastero. Allí en el exilio no hay libros como los de Roma, sino el ruido de las armas y la barbarie. En la Ciudad Eterna, las estanterías se comban por el peso de sus «hermanos» ${ }^{48}$.

Tristia, la identificación de Ovidio con su librito, es una obra de consolatio en que se reconoce con sinceridad la importancia de sus amigos, familiares y allegados, en quienes se apoya para resarcirse de la melancolía en que se halla sumido. Es una versión más honesta de la aurea mediocritas de impronta epicúrea. Los poemas insisten en el consejo de vivir sin llamar la atención, sin despertar recelo, pasando desapercibido. El poeta acepta que los suyos deben permanecer agazapados, dada la postergación a que se ve abocado. Pero también constituye una apología pretendidamente humilde de la sencillez casi anónima como modelo de vida. Las comodidades y ventajas de la fastuosidad cosmopolita de la Roma augústea se deben contrapesar con la precaución, contentarse con poco pan y poco vino. Ovidio se desnuda ante los suyos en las variadas situaciones que le corresponde padecer. Así, escribe una elegía que dirige enfermo y alejado, en el frío del confín del mundo, a su esposa. El primer verso ya señala que ni siquiera ha podido

\footnotetext{
42 «nec liber indicium est animi, sed honesta voluntas» (II, 357). Marcial escribirá: «mores non habet hic meos libellus» (XI, 15:13); «lasciva est nobis pagina, vita proba» (I, 4:8).

43 «vixque meus capiet nomina nuda liber» (II, 408).

44 «et Romanus habet multa iocosa liber» (II, 422).

45 II, 265.

46 «sex ego Fastorum scripsi totidemque libellos» (II, 549).

47 III, 14:51-52.

48 «scrinia curva» (I, 1:106). BAEZA ANGULO (2005) p. 8B explica que scrinium amplió su significado originario de «estuche en que se encierran los libros» para designar a los anaqueles en que se depositaban los volumina. Al igual que hoy, se encorvaban por el peso de los libros.
} 
escribirlo de su puño y letra, sino que lo ha dictado a un secretario. Habla de su muerte, de sus funerales y de su fracaso, pero afirma que sus libritos serán su eterno monumento, la obra que hable de él y lo recuerde para la posteridad: «maiora libelli / et diuturna magis sunt monumenta mihi» ${ }^{49}$. El último poema de toda esta obra también se remite a su esposa, insistiendo en ese concepto de inmortalidad. Los versos iniciales apelan a los libelli como monumenta para ambos. Y es que estos libritos que tanto la mencionan la harán inmortal igual que Penélope gracias a Homero.

A su hijastra Perila -a la que invoca junto a los libros en II, 437- envía una carta improvisada -o eso simula Ovidio, amarrado a su estilo «rebajado»- de tema literario, pues ella es «doctísima» ${ }^{50}$. Perila ${ }^{51}$ es también poetisa nova que compone de manera similar a las griegas clásicas. El propio Ovidio leía en casa sus poemas, como maestro y como «crítico»y seguidor. Ella está entre sus libros - «ut inter libros Pieridasque suas» ${ }^{52}-$, y la previene del daño que le han provocado sus libritos que enseñan a amar: «quia me laesere libelli» ${ }^{53}$.

La cercanía que Ovidio muestra con los suyos en Tristia es patente en el estilo. La austeridad del dístico elegíaco se une a varios recursos estilísticos: por ejemplo, sus hipérbatos son fáciles de entender; sus anáforas y paralelismos rebosan franqueza y naturalidad. Por tanto, el poema resulta escaso de artificio barroco, y concentra varias ideas con brillantez. Al mismo tiempo, las exclamaciones e imprecaciones condimentan los versos sin abuso. Se percibe en estos detalles que Ovidio compone Tristia durante su etapa de madurez, por lo que el sello de la mirada retrospectiva se suma al resto de notas ya señaladas. El de Sulmona debe contentarse con un lugar cuyo primer inconveniente es el clima, pues los inviernos en la zona del Mar Negro donde se encuentra son terribles. Por eso, el primer poema del libro V de Tristia, con tres menciones al libellus y recapitulando todas las ideas de la obra, define el nuevo volumen como afligido, al igual que la situación del autor, con la misma aridez, frío y barbarie del lugar en que se ha compuesto. Similar planteamiento de I, 11 y de V, 12 que apunta su final con un: «scribimus et scriptos absumimus igne libellos» ${ }^{54}$. Y es que, Ovidio, «embrutecido» por el entorno, ni se consuela con libros que no hay, ni tiene capacidad, ganas o destreza para componer poesía; casi resulta mejor quemar lo que se escribe, a imagen de su Ars condenada al fuego.

Explayándose con un amigo en la descripción del bárbaro entorno de Tomis -un grado de salvajismo que se contagia incluso a sus nuevos escritos ${ }^{55}-$, Ovidio recuerda sus otras obras, las urbanas, y comenta que se «representan» en el teatro. Esto produce sorpresa en el autor, pues se trataba de poesía para declamación, no para representación. Sin embargo, Plinio el Joven mencionará que sus poesías se cantan con acompañamiento

\footnotetext{
${ }^{49}$ III, 3:77-78.

50 III, 7:32.

${ }^{51}$ Quizá la misma a que se refiere BICKEL (2009) p. 782, cuando analiza las poetisas romanas de la época augústea.

52 III, 7:4.

53 Ibid. v. 27.

$54 \mathrm{~V}, 12: 60$.

55 «nec dubito quin sint et in hoc non pauca libello / barbara» (V, 7:59-60). Es el poema también catalogado como Tristia V, VIIb.
} 
de cítara y de lira ${ }^{56}$. La ductilidad sonora de aquella poesía -basada en el ritmo- permitía que se pudiera convertir fácilmente en canciones. Marcial también hará referencia al lector «qui legis et totā cantas mea carmina Romā» (V, 16:3).

En conclusión, Tristia y su tratamiento del libellus es quizá la mejor demostración de una época que ha perdido la «libertad republicana», y por tanto de un siglo cuyos intereses se centran en temas urbanos, frívolos o íntimos, y, en cierto modo, universales y hasta «modernos». Como consecuencia de este contexto, Ovidio, Tibulo, Marcial o Catulo viven otra dimensión de la amistad, de la moderación y del hedonismo, al tiempo que enarbolan una clara conciencia de la propia calidad artística. El libellus pulido y cuidado, con su esmerada redacción, será para estos poetas el puente de conexión con amigos y público. Autores como Ovidio y Marcial se esforzarán por editar libelli que destilen su mirada atenta y tersa incluso en la mera dimensión física, no sólo la literaria: en la suavidad del tacto y en la propia elaboración del papiro.

\section{BiBLIOGRAFÍA}

BicKel, Ernst (2009). Historia de la Literatura Romana, Madrid, Editorial Gredos. Traducción de José María Díaz-Regañón López.

Publio Ovidio, Nasón (1967): L'art d'aimer, edición BILINGÜe De Henri Bornecque, París, Les Belles Lettres.

- (1991). Amores (obra amatoria, volumen I), texto latino de Antonio Ramírez de Verger, traducción de Francisco Socas, Madrid, Alma Mater (Consejo Superior de Investigaciones Científicas).

- (1995). El arte de amar (obra amatoria, volumen II), texto latino de Antonio Ramírez de Verger, traducción de Francisco Socas, Madrid, Alma Mater (Consejo Superior de Investigaciones Científicas).

- (1997). Amores. Arte de amar, edición y traducción de Juan Antonio González Iglesias, Madrid, Cátedra.

- (2005). Tristezas, edición bilingüe de Eulogio Baeza Angulo, Madrid, Alma Mater (Consejo Superior de Investigaciones Científicas).

\footnotetext{
${ }^{56}$ Cfr. Epistulae IV, 19:4 y Epistulae VII, 4:9.
} 
